\title{
Quality CPR rescuer alternating every 2 minutes I minute vs university hospital clinic in San Rafael, 2018
}

\begin{abstract}
Introduction: Current guidelines established by cardiopulmonary resuscitation the American Heart Association, recommend chest compressions With Alternation Between every two minutes rescuers. In medical practice, great fatigue is observed in the providers, so it was Questioned Whether Interferes With the fatigue is quality of the Resuscitation and if a shorter Alternation would make a difference.
\end{abstract}

Materials and methods: A crossover clinical trial was paired-performed, simulating a scenario resuscitation with a high-tech simulator (manikin) where 22 couples of rescuers participated chest compressions performed WHO Alternately every minute (Scenario A) and every two minutes (Scenario B).

Results: A higher percentage of CPR was found with optimal quality in scenario B (59\% vs. $41 \%$ ). In the scenario which every two minutes, two variables related to the technique Showed significant Differences: the average depth of compressions correct $(p=0.003)$ and the percentage of compressions with sufficient depth in behalf of optimal resuscitation $(p=0.03)$. Fatigue was Described Earlier in scenario B as well as percentage of participants WHO Achieved Borg $>7$ (Subjective feeling of fatigue) in the first 4 minutes of resuscitation.

Conclusions: The AHA's current recommendation of alternating Rescuers Should be maintained every 2 minutes, recommending future investigations with larger samples to ASSESS fatigue and Its Influence on Resuscitation quality. The proper depth of chest compressions played an important role in the outcome of CPR quality.
Volume 12 Issue 4 - 2019

\author{
Miguel Sarmiento Edgar Reyes,' Catalina \\ Agathon Díaz, ${ }^{2}$ Sandra Pilar Moreno Cuineme, ${ }^{2}$ \\ Quintero Pablo Andres Oviedo ${ }^{2}$ \\ 'Resident of Epidemiology, University Foundation Juan N. Corpas, \\ Colombia \\ ${ }^{2}$ Resident of Internal Medicine, University Foundation Juan N. \\ Corpas, Colombia
}

Correspondence: Miguel Sarmiento Edgar Reyes, Internist, Master in Epidemiology, Juan N. Corpas University Foundation, Program Director of Internal Medicine Clinic Hospital Universitario San Rafael, Colombia, Tel 3164964649. Email edgar.sarmiento@ncsanrafael.com.co

Received: July 26, 2019 | Published: August 01, 2019

\section{Introduction}

Cardiopulmonary resuscitation has been practiced in many forms in history. The earliest records date back to $175 \mathrm{AD}$, Galeno being who describes the technique to inflate the lungs of a dead animal. Subsequently, the standards for resuscitation by the Royal Humane Society established in 1775 and in 1786 the sternal compressions by John Sherwin, Enfield surgeon suggested: "the surgeon should inflate the lungs and alternate compressing the breastbone". ${ }^{1}$ In 1963, the AHA (American Heart Association) and many international committees responsible for standardization of CPR training is created. The American Heart Association states that the change between rescuers practicing chest compressions in CPR should be every two minutes, to minimize rescuer fatigue and maintain high-quality chest compressions. This point has been debated since the rescuer fatigue may arise before the time set for alternation, influenced by general characteristics of the rescuer, educational level, professional experience and conditions of the stage where cardiopulmonary resuscitation (CPR) is performed.

Guidelines CPR for adults already described in the guidelines proposed by the American Heart Association ${ }^{2}$ are based on studies that include health professionals in North America and have standardized on own population characteristics, these being applied globally. To date there are no national studies to assess whether the Colombian population in the alternation of rescuer should be every two minutes or less time to ensure CPR compressions high quality. ${ }^{3-5}$
This study was conducted to determine whether the time in which the alternating rescuer performs affects the quality of actual and identify factors that may influence a negative result in the quality of chest compressions. ${ }^{6}$ This research tried to observe the relationship between the switching time of the resuscitator and the quality of chest compressions, evaluating the fatigue characteristics compressions resuscitator two simulation scenarios as close to the hospital environment with alternating every minute and every two minutes. ${ }^{7}$

\section{Materials and methods}

Couplet crossover clinical trial (Crossover Clinical Trial) was conducted with personnel in the area of health care activity they had at the University Hospital Clinic San Rafael HUCSR randomly selecting them during 2018. It was used as criteria Personal inclusion of health HUCSR (internists, residents in internal medicine, general practitioners and internal or final year students of Medicine, which were rotating in Internal Medicine), aged between 20 and 55 years and who had expressed their written consent to participate in the study. ${ }^{8,9}$ It was used as exclusion criteria cardiovascular, pulmonary, neurological and musculoskeletal diseases, in a state of pregnancy, have received negative Chronotropic drugs, sedatives or hypnotics in the past 48 hours and having any type of surgery in the last month. In this paper we sought to recreate two scenarios simulation as close to the reality of a hospital CPR process in the HUCSR; these scenarios were chest compressions with exchange between resuscitators every minute and 2 minutes, using a dummy tech (Simulator Resusci Anne) 
and supported by the AHA for training rescuers, which monitors and documents the overall quality of resuscitation, and assesses different characteristics for high-quality chest compressions, which are:

a) Total number of compressions between 100 and 120 per minute

b) Depth of compressions: between 50 and $60 \mathrm{mms}$

c) Complete thoracic Reexpanción between compressions

d) Time without compressions of no more than 30 seconds to 8 minutes

e) Correct hand position

The overall quality of resuscitation was documented by the simulator as optimal or poor as if it reached greater or equal grade of $75 \%$ in all the variables of compressions showing results for every 8 minutes simulation and recording a total value and Variable. Selection of convenience sample was determined by the availability of health personnel of Internal Medicine corresponding to 44 participants, which were randomly organized into 22 pairs. Each pair of rescuers participated in the 2 scenarios resuscitation. Double blind system was performed; resuscitators so they were not aware of the order in which the scenarios already participate statisticians analyzed data. The two scenarios clinical trial was conducted on the same day, a time including 6 hours. Each scenario resuscitation had a total of 8 minutes, with compressions performed continuously assuming the patient was with airway secured with tracheal intubation, a technician said moment which should make alternating resuscitators. One of the two scenarios would alternate every minute and another every two minutes, the order of the scenes is also selected randomly and segamiento participants. Another primary objective was to assess rescuer fatigue, so that a cardiac sensor (Polar band) was used in each participant which allowed keep track of heart rate starting 1minute before the start of the stage, recording baseline heart rates and up to one minute after resuscitation completed, allowing to determine the rate of cardiac recovery (decreased heart rate over 12 beats per minute in the first post exercise minute and determining an acceptable physical condition) it was also tested the Borg scale (subjective evaluation of fatigue) which is a numerical scale of perceived exertion or fatigue, in which 7 is a very high level of effort and should be referred by the participant during the experiment. Was considered for statistical analysis Chronotropic competence is $85 \%$ theoretical maximum heart rate established for each rescuer by TANAKA method and determines when the maximum level of physical exertion (objective assessment of fatigue) is reached, also it completed for all participants international physical activity questionnaire that evaluates IPAQ physical activity in everyday life and gives an approximation of the physical condition. ${ }^{10}$

\section{Results}

For a total of 44 participants divided into 22 pairs randomly; With regard to the characterization of the study population, $63 \%$ of participants were male, compared to educational level $36 \%$ were residents in internal medicine followed by internal (senior students of medicine) by $27 \%$. The average age was 29 years, with a minimum of 22 years and a maximum of 52 years. ${ }^{11}$ Half of the participants had a normal body mass index (BMI) and $43 \%$ overweight. In the fitness evaluation IPAQ, 50\% were high physical activity and $40 \%$ with physical inactivity (Table 1).

Table I Characterization of the study population ( $N=44)$

\begin{tabular}{|c|c|c|}
\hline Variable Sociodemographic & Characteristics & Values \\
\hline \multirow[t]{2}{*}{ Gender } & Iviasculino & $28(63.64 \%)$ \\
\hline & Memenino & $16(36.36 \%)$ \\
\hline \multirow[t]{4}{*}{ Race } & White & 0 (0_0\%) \\
\hline & African American & $3\left(6 \_82 \%\right)$ \\
\hline & Asiatic $^{\circ}$ & $0\left(0 \_0 \%\right)$ \\
\hline & Mestizo & $4 \mid\left(93 \_18 \%\right)$ \\
\hline \multirow[t]{4}{*}{ Education level } & Internal & $12(27.27 \%)$ \\
\hline & Resident Internal Medicine & $16(36.36 \%)$ \\
\hline & Specialist & $9\left(20 \_45 \%\right)$ \\
\hline & General practitioner & 7 (I5_91\%) \\
\hline Average age & 29 arlos (DE \pm 6.3 arlos) & Min 22 arlos-max 52 arlos \\
\hline Average (weight) & $73 \_0\left(\mathrm{DE} \pm 13 \_5 \mathrm{~kg}\right)$ & Min 49 kg-max III kg \\
\hline Size (average) & $169.4 \mathrm{~cm}(\mathrm{DE} \pm 8.9 \mathrm{~cm})$ & Min $150 \mathrm{~cm}-\max 185 \mathrm{~cm}$ \\
\hline \multirow[t]{4}{*}{ IMC } & Low & $0(0.0 \%)$ \\
\hline & Normal & 22 (50.0\%) \\
\hline & Overweight & $19(43.18 \%)$ \\
\hline & Obesity 3 (6_82\%) & \\
\hline \multirow[t]{3}{*}{ IPAQ } & Inactive & 18 (40_91\%) \\
\hline & Average activity & 4 (9_09\%) \\
\hline & High activity & $22\left(50 \_0 \%\right)$ \\
\hline
\end{tabular}




\section{Statistical analysis was performed by rescuer and partner}

In assessing individual performance or rescuer $(n=44)$ no statistically significant differences between the scenarios with alternating every minute vs every two minutes to compare whether failed or BORG>7as chronotropic competence were found; There was also no statistically significant difference when comparing the fatigue achieved by the rescuer subjectively achieve Chronotropic competence and rate of cardiac recovery (objective measures) in each stage and their relationship to the quality of the optimal and insufficient cardiopulmonary resuscitation (Table 2).

Table 2 Association between fatigue and conditioning variables quality resuscitation scenario $A$ and $B$

\begin{tabular}{|c|c|c|c|c|c|c|}
\hline \multirow[b]{2}{*}{ Variable } & \multirow{2}{*}{$\begin{array}{l}\text { Alternation every } \\
\text { minute - Scenario A } \\
\text { MEM } \\
\text { RGA Optima RGP> } \\
75 \% \text { ( } 9 \text { couples) ( } 8 \\
\text { individuals) }\end{array}$} & \multicolumn{5}{|c|}{ Alternation every 2 minutes - Scenario B } \\
\hline & & $\begin{array}{l}\text { RCP Insufficient } \\
<75 \% \text { ( } 13 \text { couples) ( } 26 \\
\text { individuals) }\end{array}$ & Value $\mathbf{P}$ & $\begin{array}{l}\text { Optima RGP> } 75 \% \\
\text { ( } 13 \text { couples) ( } 26 \\
\text { individuals) }\end{array}$ & $\begin{array}{l}\text { RCP Insufficient } \\
<75 \% \text { ( } 9 \\
\text { couples) (1 } 8 \\
\text { individuals) }\end{array}$ & $\begin{array}{l}\text { Value } \\
\text { P }\end{array}$ \\
\hline BORG $>7$ & $5 / 18$ individuals & $10 / 26$ individuals & 0.68 & $10 / 26$ individuals & $5 / 18$ individuals & 0.68 \\
\hline $\begin{array}{l}\text { Reach } \\
\text { Chronotropic } \\
\text { Competition }\end{array}$ & $5 / 18$ individuals & $7 / 26$ individuals & 0.77 & $7 / 26$ individuals & $4 / 18$ individuals & I \\
\hline $\begin{array}{l}\text { Achieve Cardiac } \\
\text { Recovery Rate }\end{array}$ & $13 / 18$ individuals & 23126 individuals & 0.32 & $23 / 26$ individuals & $16 / 18$ individuals & 0.66 \\
\hline
\end{tabular}

Importantly, the average minute which achieves Borg $>7$ is earlier in alternating every two minutes $(5 \mathrm{~min})$ vs alternating every minute (6min), with an equal behavior in the variable to achieve chronotropic competence. ${ }^{12}$ Which speaks of a decrease in physical performance earlier in alternating every two minutes? In assessing the fitness of each participant by the IPAQ scale objective subjective measures of fatigue $(\mathrm{BORG}>7)$ and maximum exertion level and conditioning (Chronotropic competence and heart rate recovery), there were no statistically significant differences. After 4 minutes resuscitation $2.2 \%$ $(n=1)$ of the rescuer on stage alternating every minute they expressed fatigue, versus $13 \%(n=6)$ in the stage of alternation of two minutes. Completed resuscitation 8 minutes the percentage of individuals who showed fatigue equalized in the two stages $34 \%(n=15)$. Which shows how initially during CPR there is more subjective fatigue in alternating every 2 minutes, however, in the latter half of resuscitation there is increased Rescuers describing fatigue on stage alternating every minute which equals the number of individuals with fatigue completed CPR in both scenarios.

In the same way in both scenarios with poor quality there were participants who did not achieve the subjective level or objective fatigue, thus demonstrating that the quality of chest compressions not only be related to rescuer fatigue if not the components of the art RCP. ${ }^{13}$ For analysis of the quality of resuscitation related to variables inherent to the rescuer, such as body mass index, of the 22 participants with normal BMI, 8 had an overall quality of the optimal resuscitation on stage $A$ and 12 individuals in stage $B$, a $p$ value that shows no statistically significant differences to achieve optimum quality CPR. It is noteworthy that more than half of individuals with optimal CPR on stage A and B had an abnormal BMI (overweight and obesity), and these in turn were the most expressed fatigue CPR quality. Also, it is striking that there is a higher percentage of rescuers who manage Chronotropic competition overweight and obese than in normal BMI especially those who achieve high quality CPR in both scenarios which would favor this outcome. However only $6 \%(n=3)$ of the total sample are in range of obesity, which makes comparison and with individuals with normal BMI or overweight that a considerable percentage of total resuscitators. ${ }^{14,15}$

The evaluation of results per couple; a) 22 randomly pairs were formed as follows

b) Resident-resident $\mathrm{n}=5(22.07 \%)$

c) Specialist-internal $\mathrm{n}=4(18.2 \%)$

d) Resident-internal $(n=3)(13.6 \%)$

e) Specialist-resident $(n=3)(13.6 \%)$

f) Internal-internal $(\mathrm{n}=2)(9.1 \%)$

g) GP-GP $n=2(9.1 \%)$

h) Specialist-GP $(\mathrm{n}=2)(9.1 \%)$

i) Internal-GP $\mathrm{n}=1(4.55 \%)$

In evaluating the performance pairs $(n=22)$ the following results were found in both Scenario A and Scenario B.

PCR with optimal quality was higher (59\%) in stage alternating every two minutes in the alternating every minute $(40.9 \%)$ without showing a statistically significant difference $(\mathrm{p}=0.84) .{ }^{16}$ In addition to compare variables correct technique compressions specifically couples with one optimal RCP achieved in both scenarios was no statistically significant difference (Table 3). Comparing again each variable technique that determines the quality of $\mathrm{CPR}$ on each scenario A, there was no variable showed significant difference, while in stage B statistically significant difference was evident in the variables average depth of correct compressions ( $\mathrm{p}=0.003$ OR 95\% CI 2.2-1121 $50)$ and percentage of compressions with sufficient depth ( $\mathrm{p}=0.03$; 95\% CI OR 9 1.38-58), which shows that there is an increased risk that the quality of the compressions and finally CPR is affected when the depth of compressions is not correct (Table 4). This may indicate that the depth of compressions was technically determined what the highest percentage of high quality CPR specifically on stage B or alternation 2minutes. ${ }^{17}$ In assessing performance in pairs, on stage $\mathrm{A}$ and $\mathrm{B}$ there was no statistically significant link the Borg $>7$ variables, Chronotropic achieve competition and achieve recovery heart rate with optimal CPR or CPR with poor difference. ${ }^{18}$

When comparing couples who achieve optimal CPR on stage A and $\mathrm{B}$ depending on the type of partner for schooling was no statistically significant difference was found. ${ }^{19}$ 
Table 3 RCP optimal quality in both scenarios, Comparison determinants of CPR technique in each scenario with a final result of optimal quality CPR variables

\begin{tabular}{|c|c|c|c|}
\hline \multirow[t]{2}{*}{ Variables } & \multirow{2}{*}{$\begin{array}{l}\text { Scenario A (Alternate every minute) } \\
\text { RCP Quality> 75\% } 9 / 22 \text { couples ( } 41 \% \text { ) }\end{array}$} & \multicolumn{2}{|c|}{ Scenario B (Alternation every 2 minutes) } \\
\hline & & $\begin{array}{l}\text { RCP Quality> 75\% I3/22 } \\
\text { couples }(59 \%)\end{array}$ & VALUE P 0.84 \\
\hline $\begin{array}{l}\text { Total number of appropriate compressions in } 8 \text { mins } \\
\text { (between } 800 \text { and } 960 \text { ) }\end{array}$ & $6 / 9(66 \%)$ & 10113 (77\%) & 0.96 \\
\hline $\begin{array}{l}\text { Percentage of compressions with adequate HR>75\% } \\
\text { (between } 100 \text { and } 120 / \mathrm{min} \text { ) }\end{array}$ & $619(66 \%)$ & $5 / 13(38 \%)$ & 0.38 \\
\hline $\begin{array}{l}\text { Average HR of compressions per correct minute } \\
\text { (between } 100 \text { and } 120 \mathrm{Imin} \text { ) }\end{array}$ & $6 / 9(66 \%)$ & $9 / 13$ (69\%) & 0.73 \\
\hline $\begin{array}{l}\text { Average compression depth correct (between } 50 \text { and } \\
60 \mathrm{~mm} \text { ) }\end{array}$ & $8 / 9(89 \%)$ & $13 / 13(100 \%)$ & 0.84 \\
\hline $\begin{array}{l}\text { Percentage of compressions with correct expansion> } \\
75 \%\end{array}$ & $5 / 9(55 \%)$ & $4 / 13$ (31\%) & 0.47 \\
\hline $\begin{array}{l}\text { Percent of compressions with sufficient depth } \\
\text { between } 50 \text { and } 60 \mathrm{~mm}>75 \%\end{array}$ & $619(66 \%)$ & $10113(77 \%)$ & 0.96 \\
\hline
\end{tabular}

Table 4 overall result of quality CPR Scenario A and B. Comparison of variables determining CPR technique in each scenario according to the final result of optimal or poor quality CPR

\begin{tabular}{|c|c|c|c|c|c|c|}
\hline \multirow{2}{*}{ Variables } & \multirow{2}{*}{$\begin{array}{l}\text { Scenario A (Alternate } \\
\text { every minute) } \\
\text { RCP Quality> 75\% } 9 / 22 \\
\text { couples (4I\%) }\end{array}$} & \multicolumn{5}{|c|}{ Scenario B (Alternation every 2 minutes) } \\
\hline & & $\begin{array}{l}\text { RCP Quality> } \\
75 \% 13 / 22 \\
\text { couples (59\%) }\end{array}$ & VALUE P & $\begin{array}{l}\text { RCP Quality> } 75 \% \\
\text { I3 I } 22 \text { couples } \\
(59 \%)\end{array}$ & $\begin{array}{l}\text { RCP Quality } \\
<75 \% 9122 \\
\text { couples ( } 41 \%)\end{array}$ & Value $\mathbf{P}$ \\
\hline $\begin{array}{l}\text { Total number of appropriate } \\
\text { compressions in } 8 \text { mins } \\
\text { (between } 800 \text { and } 980 \text { ) }\end{array}$ & $619(66 \%)$ & 5/I3 (38\%) & 0.38 & 10/13 (77\%) & $6: 9(66 \%)$ & 198 \\
\hline $\begin{array}{l}\text { Percentage of compressions } \\
\text { with adequate HR> } 75 \% \\
\text { (between } 100 \text { and } 1211 \text { / } \\
\text { min) }\end{array}$ & $810(58 \%)$ & an $(23 \%)$ & 0.1 & $5 / 13(38 \%)$ & I/0 (II\%) & 0.35 \\
\hline $\begin{array}{l}\text { Average HR of } \\
\text { compressions per correct } \\
\text { minute (between } 100 \text { and } \\
\text { I20Imin) }\end{array}$ & 8/9 (88\%) & $5113(38 \%)$ & 0.38 & $9 / 1309 \%)$ & $3 / 9(33 \%)$ & $0 / 1$ \\
\hline $\begin{array}{l}\text { Average compression depth } \\
\text { correct (between } 50 \text { and } \\
60 \mathrm{~mm} \text { ) }\end{array}$ & $8 / 0$ (89\%) & 9)। 3 (69\%) 0.57 & & $13 / 13(100 \%)$ & $3 / 0(33 \%)$ & 0.003 \\
\hline $\begin{array}{l}\text { Percentage of compressions } \\
\text { with correct expansion> } \\
75 \%\end{array}$ & $5 / 9(55 \%)$ & IIIII3 \{85\%) & 0.3 & $4 / 1301 \%)$ & 719 (78\%) & 0 \\
\hline $\begin{array}{l}\text { Percent of compressions } \\
\text { with sufficient depth } \\
\text { between } 50 \text { and } 80 \mathrm{~mm}> \\
75 \%\end{array}$ & $8 / 9(08 \%)$ & $8113(62 \%) 0.83$ & & $10113(77 \%)$ & $2 / 9(22 \%)$ & 0.03 \\
\hline $\begin{array}{l}\text { Tiernpo correct }{ }^{\circ} \text { without } \\
\text { compressions during the } 8 \\
\text { reins (from I to } 30 \mathrm{sec} \text { ) }\end{array}$ & 919 (100\%) & $13113(100 \%)$ & $\begin{array}{l}\text { No es } \\
\text { posible }\end{array}$ & $9 t 9(100 \%)$ & $13 / \mid 3(100 \%\}$ & $\begin{array}{l}\text { No as } \\
\text { posible }\end{array}$ \\
\hline $\begin{array}{l}\text { Percentage decompressions } \\
\text { with correct position of } \\
\text { hands in } 8 \text { mins }>75 \%\end{array}$ & $919(100 \%)$ & $13113(100 \%)$ & $\begin{array}{l}\text { No es } \\
\text { posible }\end{array}$ & $9 / 9(100 \%)$ & $719(78 \%)$ & 0.45 \\
\hline
\end{tabular}




\section{Discussion}

In this study several significant results were found in first instance against the primary outcome despite the existence of higher quality CPR alternating every two minutes no statistically significant difference in the two scenarios. Two variables related to the technique showed significant differences: the average depth of compressions correct and the percentage of compressions deep enough for optimal resuscitation on stage alternating every two minutes. However, it is very striking as although the individuals who participated in this study were aware of the guidelines established by the AHA for CPR quality only $59 \%$ achieve optimal CPR on stage A and $41 \%$ on stage B. On the other hand, fatigue (measured subjectively and objectively) showed no statistically significant relationship in any of the two scenarios or relationship with the end result of CPR. But it is worth noting that fatigue was expressed earlier in the group with alternating every two minutes equaling the proportions in the two groups at the end of CPR. When comparing our results with the only similar study conducted in Sydney, Australia in $2007^{14}$ our results are consistent because in this the effectiveness of compressions in two stages alternating every two minutes and every minute was evaluated duration of 8 minutes showing no significant difference in the number of effective by comparing two scenarios compression, a higher percentage of rescuers said past fatigue four minutes resuscitation stage alternating every two minutes (44\%) vs (27\%) was also determined in alternating every minute. Although CPR is an important issue, it is assumed that it is a topic that all health personnel knows and masters. Moreover, despite the magnitude of its importance, not much emphasis on studies that measure the factors that could influence high quality compressions alternating especially rescuer. Limitations in this study lie in the small sample size, since despite the methodological rigor of the study; the available population reached to form 22 couples was included in the study. On the other hand, performance analysis and CPR quality was evaluated by the final result given by the mannequin in pairs. It is impossible to analyze the individual performance of each participant on the outcome of CPR.

\section{Conclusion}

There were no statistically significant differences in the overall quality of resuscitation comparing alternation between Rescuers every minute vs every two minutes, No statistically significant differences when comparing the objective and subjective evaluation of fatigue differences were found, however it is emphasized that the average minute in which is achieved Borg $>7$ (objective fatigue) is earlier in alternating every two minutes, with the same behavior Chronotropic competence (subjective fatigue), which speaks of a decrease in the earliest physical performance in alternating every two minutes however, it did not correlate with the overall quality of resuscitation. While it is concluded that should keep the current recommendation of the AHA of alternating rescuers every 2 minutes to perform chest compressions, there is a margin of doubt versus how could modify the results of this study, if replicated with a larger sample, increased stress for the rescuer and longer resuscitation. Finally, considering that CPR is a skill that must be optimally handled by all medical personnel working in a hospital environment, finding the 22 reanimations performed at each stage only 59\% (13 reanimations) achieved a level adequate quality of resuscitation, leaves the question if need more training in this field and strengthening education and dissemination of the guidelines of the AHA CPR to optimize in this way a successful and equivalently result impact on patient survival.

\section{Acknowledgments}

None.

\section{Conflicts of interest}

Authors declare that there is no conflict of interest.

\section{Funding}

None.

\section{References}

1. Maier GW, Tyson GS, Olsen CO, et al. The physiology of external cardiac massage: High impulse cardiopulmonary resuscitation. Circulation. 1984;70(1): 86-101.

2. Zinski HMF, Sayre MR, Chameides L, et al. highlights. Circulation. $2015 ; 123: 34-47$

3. Vallejo-Manzur F, Varon J, R Fromm P. Moritz Schiff Baskett and the history of open chest cardiac massage. Resuscitation. 2002; 53(1):3-5.

4. Figl M, LE Pelinka W. Mauritz Franz Koenig and Friedrich Maass. Resuscitation. 2006;70(1):6-9.

5. Berryman E. Evolution of CPR. Online CPR Training Center certification. 2015 .

6. McDonald $\mathrm{CH}$, Heggie J, Jones CM, et al. Hulme Rescuer fatigue under the ERC 2010 guidelines, and Its effect on cardiopulmonary resuscitation (CPR) performance. Emerg Med J. 2013; 30(8):623-627.

7. Abella BS, Sandbo N, Vassilatos P, et al. Chest Compression Cardiopulmonary Resuscitation During Rates Are Suboptimal. Circulation. 2005; 111(4):428-434.

8. AJ Handley, Handley JA. The Relationship Between rate of chest compression and compression: relaxation ratio. Resuscitation. 1995; 30(3):237-241

9. Gutwirth H, Williams B, Boyle M. Rescuer Fatigue in Cardiopulmonary Resuscitation: A Review of the Literature. Australis J Paramed. 2009;7(4):1-9.

10. Castelao Fernandez E, Russo SG, Cremer S, et al. Positive Impact of Crisis Resource Management training on non flow time and team member verbalisations During simulated cardiopulmonary resuscitation: A randomized controlled trial. Resuscitation. 2011;82(10):1338-1343.

11. Tschan F, M Vetterli, Semmer NK, et al. Activities During interruptions in cardiopulmonary resuscitation: A simulator study. Resuscitation. 2011;82(11):1419-1423.

12. A Ashton, McCluskey A, Gwinnutt CL, et al. Effect of rescuer fatigue on performance of chest compressions external continuous over $3 \mathrm{~min}$. Resuscitation. 2002;55(2):151-155.

13. Souchtchenko SS, Benner JP, Allen JL, et al. A review of chest compression interruptions During out of hospital cardiac arrest and strategies for the future. J Emerg Med. 2013;45 (3):458-466.

14. Manders S, Geijsel FEC. During continuous alternating chest compressions providers for cardiac arrest: Every minute or every two minutes? Resuscitation. 2009; 80(9):1015-1018.

15. Kent Braun JA, Fitts RH, Christie A. Skeletal muscle fatigue. Compr Physiol. 2012;2(2):997-1044.

16. Buoys S, Guével A. Neuromuscular fatigue in healthy muscle: Underlying Mechanisms factors and adaptation. Ann Phys Rehabil Med 2011; 54 (2):88-108. 
17. World Health Organization. Non communicable Disease Risk Factor Survey Myanmar 2009. 2011. p. 46-56.

18. Summary Statistics heart disease and stroke American heart. 2017. pp. 2-7.
19. Navarro Vargas JR, Hue H Camacho J. Esquivel Manual Osorio clinical practice based on evidence: Resuscitation cardiocerebropulmonar. Rev Colomb Anestesiol. 2015;43(1):9-19. 